\title{
Student Evaluations of the Courses in Medical Psychology at the Medical Department of the RWTH Aachen: A Three-Year Report
}

\author{
Anne Scherer ${ }^{1}$, Thomas Forkmann ${ }^{1}$, Sandra Sudmann², Siegfried Gauggel ${ }^{1}$ \\ ${ }^{1}$ Institute of Medical Psychology and Medical Sociology, \\ University Hospital of the Rheinisch-Westfälische Technische Hochschule Aachen, Aachen, Germany \\ ${ }^{2}$ Dean's Office, Medical Faculty, Rheinisch-Westfälische Technische Hochschule Aachen, Aachen, Germany \\ Email: ascherer@ukaachen.de
}

Received June 6, 2012; revised July 20, 2012; accepted August 10, 2012

\begin{abstract}
Introduction: With the introduction of a new curriculum "Modellstudiengang Medizin" in Aachen, the education in medical psychology was also restructured. This paper presents data from the students' evaluations of the Basic Course in Medical Psychology and the new teaching format "Systemblock Psyche" over a three-year time span. Method: All students were asked to evaluate the courses anonymously online. Effect sizes [1] were calculated to compare acceptance of the different course types and also changes across time. Results: Both the Basic Course in Medical Psychology and the Systemblock Psyche were rated as "good" to "satisfactory" and were in their overall acceptance comparable to other courses and system blocks. Continuous improvement in acceptance was found for the Basic Course $(d=0.30-0.57)$. The Systemblock Psyche received varying evaluations but achieved higher scores on comprehensibility $(d=0.20)$ and communication among teachers $(d=0.34)$ than other system blocks. On the other hand, students rated the education in medical psychology as less relevant than other courses $(d=0.28$ and 0.77 , respectively). Conclusion: Overall, the acceptance rating was satisfactory and comparable to other evaluation studies conducted in earlier curricula. However, ratings of the relevance of the courses in medical psychology were disappointing and indicate the difficulty of teaching a biopsychosocial model to medical students.
\end{abstract}

Keywords: Teaching Evaluation; Education in Medical Psychology; Modellstudiengang; Systemblock

\section{Introduction}

With the new medical licensure act of 2002, a change in medical curricula occurred in the German universities. At the Rheinisch-Westfälische Technische Hochschule Aachen (RWTH), 240 new medical students have begun a new, revised curriculum (called Modellstudiengang) each year since the winter semester of 2003/2004. The most important innovation the medical licensure act was to erase the division between a pre-clinical and a clinical phase of the curriculum. With the division intact, students had to wait for two years until their first contact with live patients, which was detrimental to motivation and identification with the profession. Additionally, before the reform, students were often taught about the same organ or system by different medical departments (i.e., anatomy first, then physiology a semester later and pathology a few semesters afterward), making it difficult to integrate the knowledge that was acquired over a long period of time.

In the new curriculum of the RWTH Aachen, the focus is on organ- and system-centred learning and teaching.
The traditional split between a pre-clinical and a clinical phase, organised by different medical departments, was abandoned in favour of an interdisciplinary, interlocked learning spiral [2].

In the first phase of the learning spiral (1st and 2nd semesters), students are instructed in relevant basic medical subjects, for example, biology, physics and cellular biology. This phase of the curriculum was designed to equalise the students' abilities [3].

During the second phase of the learning spiral, most teaching is done in a new teaching format, the interdisciplinary "system blocks", which take several weeks each. These system blocks introduce different organs or organ systems (e.g. the skin, gastro-intestinal system and psyche) and include various clinical examples. Each system block is organised by a coordinator who is assisted in their task by representatives from other disciplines. System blocks are a key element of the Modellstudiengang in Aachen.

The changes in the structure of the curriculum are a challenge as well as a chance for providing education in 
medical psychology. Few other German universities revised the curriculum for all new students instead of just a small group. One of the challenges is the complex, interdisciplinary organisation of the courses and the necessary coordination between the former pre-clinical and clinical teachers and subjects (e.g. medical psychology, psychiatry and psychotherapy, psychosomatic medicine) in a joint course. One of the opportunities is to focus on important key knowledge and to teach it using both theoretical instruction and concrete case studies [4].

After the reform, medical psychology is mainly taught in two courses: a Basic Course in Medical Psychology during the 2nd semester and the Systemblock Psyche during the 5th semester. Most of the teaching is done by psychologists, whereas due to the course structure other professions (such as psychiatrists, medical historians, palliative care professionals) are involved in the teaching in medical psychology. The basic concepts are taught via lectures, seminars and skills training. The focus is on teaching the biopsychosocial model of psychological processes and on basic methodological and scientific knowledge.

The Basic Course in Medical Psychology consists of 28 classes, 24 of which are taught as lectures and four as seminars. The Basic Course teaches methodological principles (scientific thinking, experiments) using applied clinical examples. Additionally, important facts about the history of psychology and psychiatry, normal and disordered behaviour, psychodiagnostics, neuropsychology, memory, learning, cognition, intelligence, motivation, emotion, personality and psychological development are taught. In the accompanying seminar, students practise administering, analysing, and interpreting psychological tests.

The Basic Course is organised by the department of medical psychology in cooperation with the department of psychiatry, psychotherapy and psychosomatics and the department of child and adolescent psychiatry and psychotherapy. Special focus is on presenting real patients, so that students in their second semester at university can already see the connection between theory and practical work. Students must write a psychological report using actual test results and they must take a multiple-choice exam in order to pass the course.

The Systemblock, which is taught three semesters later, consists of 64 classes (44 hours of lectures, 20 hours of seminars). The focus of the Systemblock Psyche is on conveying basic comprehension of mental disorders (depression, alcohol abuse, attention deficit disorder and schizophrenia) and their treatment, because of their major importance in clinical practice.

Like the Basic Course, the system block is taught by an interdisciplinary team with a focus on case studies. This course is also coordinated by the department of medical psychology. Also involved are the department of psychiatry, psychotherapy and psychosomatics; the department of child and adolescent psychiatry and psychotherapy; the department of palliative medicine; the institute of history, theory and ethics in medicine and the institute of pharmacy and toxicology. Students must pass a multiple-choice exam at the end of the course. Knowledge about its content is required in order to pass the Objective Structured Practical Examination (OSPE) at the end of the second phase of the curriculum after the sixth semester.

With all new courses in the new Modellstudiengang, it is important to know about students' acceptance, and the courses in medical psychology are no exception. The course evaluation provides information to allow for continuous improvement. The present paper gives an overview of the development of students' acceptance of the courses during the three years in which they have been taught (summer semester 2005 to summer semester 2008).

\section{Method}

\subsection{Participants}

Each semester, an average of 240 students have been asked to evaluate the courses they took. Approximately $62 \%$ were female. It was mandatory for all students to complete an online evaluation form ("Evaluna") to indicate whether they wanted to anonymously evaluate a course or not. The evaluation itself was not mandatory. The return rates for the courses in medical psychology were good $(79.3 \%$ in summer semester 07 to $87.7 \%$ in summer semester 05).

\subsection{Questionnaire}

A questionnaire for assessing students' acceptance was developed with the aim of using as few questions as possible to cover the most important aspects of acceptance of single courses (Cronbach's $\alpha=0.93$ ). The core questionnaire covers the following topics: Attendance, additional time investment, comprehensibility of the material, structure of the overall course, communication among teachers, overall grade, relevance and personal learning. The question about personal learning was included from the winter semester 2006/2007. A question about the relevance of the course was omitted from summer semester 2007. With the exception of attendance (attended less than $50 \%$, between $50 \%$ and $75 \%$ or more than $75 \%$ of the classes) and time investment (no additional time investment, less than one hour a week, more than one hour a week), all questions were answered on a 1-to-6 rating scale corresponding to the German grading system, where 1 is the best possible grade ("very good") and 6 
the worst possible grade (“deficient").

\subsection{Statistical Analyses}

We calculated descriptive statistics, i.e., means (M) and standard deviations (SD). To determine whether changes over time were meaningful, effect sizes $(d)$ and confidence intervals (CI) were estimated according to the formula developed by Hedges and Olkin [1]. Effect sizes allow the magnitude of differences to be estimated and are less susceptible to sample-size variations than tests of significance. In the present evaluation, effect sizes were chosen over classical tests of significance to ensure a conservative estimate of effects that was not biased by the large sample size. Cohen recommends interpreting effect sizes as follows: $0.20<d \leq 0.50$ is small, $0.50<d \leq$ 0.80 is medium and $d \geq 0.80$ is large [5]. All analyses were conducted using SPSS 17.0 or SAS 9.1.

\section{Results}

\subsection{Basic Course in Medical Psychology}

The Basic Course was rated between 2.1 (SD 1.0, comprehensibility summer semester 08) and 2.9 (SD 1.0, personal learning summer semester 07 , structure summer semester 05) (Table 1).

There were continuous improvements in ratings except for the communication item. Comparisons between the first and the last evaluation showed meaningful improvements for the overall score $(d=0.33, \mathrm{CI}=0.14$ $0.53)$, comprehensibility $(d=0.40, \mathrm{CI}=0.21-0.59)$, structure $(d=0.57, \mathrm{CI}=0.37-0.76)$ and communication $(d=0.30, \mathrm{CI}=0.10-0.49)$.

Comparisons of the acceptance of the Basic Course and the other courses during the first phase of the Mod- ellstudiengang showed a meaningful difference in favour of the Basic Course for comprehensibility $(d=0.25, \mathrm{CI}=$ $0.18-0.31)$. On the other hand, the course was judged to be less relevant $(d=0.28, \mathrm{CI}=0.17-0.38)$. Apart from this, we found no meaningful differences.

About $44 \%$ of the students attended more than $75 \%$ of the classes-for the other courses of the first phase, $82.1 \%$ attended more than $75 \%$ of the classes. Only $16.9 \%$ of the students spent more than one hour a week on additional work, compared to $70 \%$ in the other courses of phase 1 (Table 2).

\subsection{Systemblock Psyche}

The Systemblock Psyche achieved ratings between 2.0 (SD 0.7, comprehensibility winter semester 06/07) and 2.8 (SD 1.0, overall score winter semester 05/06). Results improved in all areas between winter semester 05/06 and winter semester 06/07. Comprehensibility improved meaningfully between the first and the last evaluation $(d=0.28, \mathrm{CI}=0.07-0.50)$. On the overall rating, structure and personal learning showed no meaningful difference from the other system blocks. The Systemblock Psyche was evaluated better than other courses on comprehensibility $(d=0.20, \mathrm{CI}=0.11-0.29)$ and communication among teachers $(d=0.34, \mathrm{CI}=0.24$ $0.43)$. The students rated the Systemblock Psyche as less relevant $(d=0.77, \mathrm{CI}=0.62-0.93)$. As in the Basic Course, students attended fewer lessons in the system block Psyche compared to other system blocks (Table 2; More than $75 \%$ of the classes: Systemblock Psyche $75.8 \%$, other system blocks $84.7 \%$ ).

The number of students who invested more than one additional hour a week was smaller as well $(82.3 \%$ compared to $91.8 \%$ ).

Table 1. Ratings of the basic course in medical psychology and the systemblock psyche between SS 2005 and SS 2008.

\begin{tabular}{|c|c|c|c|c|c|c|c|c|c|c|c|c|c|c|c|c|c|c|}
\hline \multirow[b]{2}{*}{ Semester } & \multicolumn{3}{|c|}{ Overall Score } & \multicolumn{3}{|c|}{ Comprehensibility } & \multicolumn{3}{|c|}{ Structure } & \multicolumn{3}{|c|}{ Communication } & \multicolumn{3}{|c|}{ Personal Learning } & \multicolumn{3}{|c|}{ Relevance } \\
\hline & M & SD & $\mathrm{N}$ & M & SD & $\mathrm{N}$ & M & SD & $\mathrm{N}$ & M & SD & $\mathrm{N}$ & M & SD & $\mathrm{N}$ & M & SD & $\mathrm{N}$ \\
\hline \multicolumn{19}{|c|}{ Ratings of the basic course in medical psychology } \\
\hline SS 2005 & 2.7 & 0.9 & 221 & 2.5 & 1.0 & 229 & 2.9 & 1.1 & 223 & 2.6 & 1.1 & 213 & - & - & - & 2.8 & 1.0 & 227 \\
\hline SS 2006 & 2.6 & 1.0 & 186 & 2.4 & 1.1 & 189 & 2.7 & 1.1 & 186 & 2.8 & 1.2 & 177 & - & - & - & 2.7 & 1.1 & 190 \\
\hline SS 2007 & 2.5 & 0.9 & 194 & 2.2 & 0.9 & 193 & 2.3 & 0.9 & 191 & 2.2 & 0.9 & 154 & 2.9 & 1.0 & 194 & - & - & - \\
\hline Mean & 2.6 & 0.9 & 802 & 2.3 & 1.0 & 806 & 2.5 & 1.1 & 793 & 2.5 & 1.1 & 719 & 2.8 & 1.1 & 388 & 2.7 & 1.0 & 417 \\
\hline $\begin{array}{c}\text { Mean other } \\
\text { 1st phase courses }\end{array}$ & 2.7 & 1.1 & 5549 & 2.6 & 1.2 & 5604 & 2.5 & 1.2 & 5570 & 2.6 & 1.2 & 5570 & 2.6 & 1.2 & 3309 & 2.4 & 1.1 & 2265 \\
\hline \multicolumn{19}{|c|}{ Ratings of the systemblock psyche } \\
\hline WS 05/06 & 2.8 & 1.0 & 164 & 2.6 & 1.1 & 162 & 2.7 & 1.2 & 162 & 2.6 & 1.1 & 157 & - & - & - & 2.6 & 1.1 & 162 \\
\hline WS 06/07 & 2.3 & 0.9 & 181 & 2.0 & 0.7 & 179 & 2.3 & 0.9 & 177 & 2.2 & 0.9 & 166 & 2.4 & 1.0 & 175 & - & - & - \\
\hline WS 07/08 & 2.6 & 1.1 & 165 & 2.3 & 1.0 & 166 & 2.6 & 1.2 & 166 & 2.4 & 1.0 & 155 & 2.7 & 1.2 & 163 & - & - & - \\
\hline Mean & 2.6 & 1.0 & 510 & 2.3 & 1.0 & 507 & 2.5 & 1.2 & 505 & 2.4 & 1.0 & 478 & 2.5 & 1.1 & 338 & 2.6 & 1.1 & 162 \\
\hline $\begin{array}{c}\text { Mean other } \\
\text { system blocks }\end{array}$ & 2.6 & 1.0 & 3704 & 2.5 & 1.0 & 6451 & 2.7 & 1.2 & 6433 & 2.8 & 1.2 & 6238 & 2.3 & 1.1 & 3704 & 1.9 & 0.9 & 6433 \\
\hline
\end{tabular}


Table 2. Attendance and time investment in the basic course in medical psychology and the systemblock psyche.

\begin{tabular}{ccccccc}
\hline & \multicolumn{3}{c}{ Attendance in \% } & \multicolumn{5}{c}{ Time investment in \% } \\
\hline & under 50 $50-75$ & over 75 & $0 \mathrm{~h}$ & $<1 \mathrm{~h}$ & $>1 \mathrm{~h}$ \\
\hline $\begin{array}{c}\text { Basic course in } \\
\text { medical } \\
\text { psychology }\end{array}$ & 27.9 & 27.8 & 44.2 & 34.2 & 48.9 & 16.9 \\
$\begin{array}{c}\text { Mean other 1st } \\
\text { phase courses } \\
\begin{array}{c}\text { Systemblock } \\
\text { psyche }\end{array}\end{array}$ & 5.6 & 12.3 & 82.1 & 9.0 & 20.9 & 70 \\
$\begin{array}{c}\text { Mean other } \\
\text { system blocks }\end{array}$ & 2.8 & 12.5 & 84.7 & 1.7 & 6.5 & 91.8 \\
\hline
\end{tabular}

\section{Discussion}

The courses in medical psychology in the Modellstudiengang Medizin in Aachen were rated on acceptance with scores "good" (2) to "satisfactory" (3) in their German interpretation during the first three years of their existence.

The ratings of the Basic Course in Medical Psychology improved continuously on most scales. Compared to other courses during the first phase of the curriculum, the course was rated as easier to understand. The Systemblock Psyche in the second phase of the curriculum also improved after the first year, but received worse scores in the third year. Compared to other system blocks, the block was judged to be more comprehensible and the teachers were judged to have better communication. It is striking that in spite of good overall evaluation results, the courses in medical psychology were rated worse than other courses on relevance and that students invested less time. This is probably explained by the fact that for other courses, more content is included, and some courses have additional quizzes and more demanding exams. Another explanation is that the lower score is due to an understandable focus of medical students on biological subjects (see [6] - "bio instead of psychosocial").

With the present data, we can make no assumption about whether the student ratings correspond to the students' exam results, because the anonymity of the student data does not allow comparisons to be made with exam results. Future longitudinal analyses might help in gaining insight into this issue.

This study shows good to satisfactory results for the acceptance of the education in medical psychology, which is comparable to that obtained in other universities. Strehl and Kübler [7] found results for seminars in medical psychology in Tübingen that were in the upper part of a seven-point Likert scale. The curriculum in medical psychology of the University of Mainz was rated good and to be especially "important for the medical career" [8]. A survey at the University of Leipzig showed that contact with patients and communication training were rated by students as the most important component of the education in medical psychology [9].

In the medical psychology curriculum in Aachen, communication training is not included, because the structure of the Modellstudiengang allow neither time nor resources for it. Integration of communication training would mean that theoretical and methodological content would have to be omitted, which would be problematic. Nonetheless, the medical students in Aachen can chose communication training as an optional subject taught in the Aachen Skillslab. The curriculum is organised by an interdisciplinary team representing different departments (medical psychology, general medicine, emergency medicine).

In summary, this study showed good to satisfactory acceptance of the curriculum in medical psychology among the students at RWTH Aachen. The new curriculum makes it possible to include clinical content much earlier in the curriculum and the interdisciplinary teaching and learning encourages students to discover different perspectives on the subject. The ongoing course evaluation affords an opportunity for the content of the courses to be improved and their perceived relevance to be enhanced.

\section{REFERENCES}

[1] L. V. Hedges and I. Olkin, "Statistical Methods for MetaAnalysis," Academic Press, Orlando, 1985.

[2] J. Noth, "Der Aachener Modellstudiengang Medizin," Forschung \& Lehre, Vol. 5, No. 5, 2009, p. 352.

[3] S. Beckers, J. Bickenback, M. Fries, N. Hoffmann, B. Classen-Linke, B. Killersreiter, R. Wainwright, R. Kuhlen and R. Rossaint, "Meet the AIX-PERTS. Der Notfallmedizinische Start in den Modellstudiengang $\mathrm{Hu}$ manmedizin am Universitätsklinikum Aachen," Der Anaesthesist, Vol. 53, No. 6, 2004, pp. 561-569.

[4] B. Strauß and V. Köllner, "Die Neue Approbationsordnung: Eine Chance für psychosoziale Fächer," Psychotherapie, Psychosomatik und Medizinische Psychologie, Vol. 53, No. 2, 2003, pp. 43-46. doi: $10.1055 / \mathrm{s}-2003-36967$

[5] J. Cohen, "Statistical Power for the Behavioural Science," 2nd Edition, Erlbaum, Hillsdale, 1985.

[6] G. A. Fava and N. Sonino, "The Biopsychosocial Model Thirty Years Later," Psychotherapy and Psychosomatics, Vol. 77, No. 2, 2008, pp. 126-127.

[7] U. Strehl and A. Kübler, "Projektbericht Seminar Medizinische Psychologie," Zeitschrift für Medizinische Psychologie, Vol. 19, No. 2, 2010, pp. 90-93.

[8] S. Fischbeck, "Das Mainzer Unterrichtskonzept der Me- 
dizinischen Psychologie und Medizinischen Soziologie," Zeitschrift für Medizinische Psychologie, Vol. 15, No. 1, 2006, pp. 21-26.

[9] O. Decker and K. Rockenbauch, "Das Neue Lehrkonzept für Medizinische Psychologie und Medizinische Soziolo- gie an der Universität Leipzig_Erste Eindrücke und Evaluation," Zeitschrift für Medizinische Psychologie, Vol. 15, No. 1, 2006, pp. 27-30. 